Tamara Atkin and Laura Estill, eds. Early British Drama in Manuscript. Turnhout: Brepols, 2019. British Manuscripts 1. Pp. xvi, 376. Hardback, €100. ISBN 9782503575469. https://doi.org/10.1484/M.BM-EB.5.113206

\title{
BRETT GREATLEY-HIRSCH
}

University of Leeds

As the eagerly anticipated flagship volume of 'British Manuscripts', a new series published by Brepols under the editorship of A.S.G. Edwards, Early British Drama in Manuscript exceeds expectations and sets a high standard for future volumes. The essays in Early British Drama in Manuscript showcase the variety and vibrancy of research into early British dramatic texts, paratexts, and contexts using manuscript evidence. Along with twenty-one other contributors, Tamara Atkin and Laura Estill have produced a volume of scholarship that is interdisciplinary without being inaccessible and meticulous without stifling excitement for the material.

Scholarship often treats 'manuscript' as a 'monolithic category'; as Atkin and Estill remind us in their Introduction, however, the term is 'a catch-all' in this context 'for a variety of types of evidence', including 'playtexts, actors' parts, onstage props, records, and other accounts that can be used to adduce performance' (1). Essays attend to all of these types of evidence and, although there is frequent overlap, the collection divides into three sections - 'Production', 'Performance', and 'Reception'. Given the cultural and disciplinary privileging of print, it is easy to forget that 'the bulk of our knowledge of early performance necessarily comes to us from manuscript sources' (2), a fact made all the more sobering in light of the low rate of manuscript survival from the period. Atkin and Estill admit, 'for some plays, the only evidence we have that they once existed derives from manuscripts' (2). This acknowledgement makes the absence of a chapter on lost plays ironically conspicuous from what is otherwise a comprehensive collection. Since manuscript evidence 'is like a piece of a puzzle' that will never be complete, our duty as scholars is to re-evaluate those pieces we have and be alert to the possibility of discovering and examining new ones, which, taken together, might allow us to better see 'the shapes and colours of the original picture of early dramatic composition, performance, and reception' (1).

Essays in the 'Production' section share an interest in exploring the status of playbooks and their relation to performance, whether real or imagined. In a departure from previous studies focusing on the Book of Brome (Yale Beinecke MS 365) in the context of its later additions and readership, Joe Stadolnik's chapter 
(19-32) sets out to investigate 'what kind of book Brome was first made to be' by concentrating on 'the manuscript's earlier stage of production' (21). Having demonstrated it to be 'seemingly useless as a performance script', Stadolnik concludes that 'the Brome Abraham and Isaac is medieval drama as manuscript', as 'a textual genre circulating as an article for private reading' (30). Pamela M. King's chapter (33-54) offers a detailed codicological description of two manuscript witnesses to the Coventry Weavers' pageant towards 'a consideration of how radically different as a manuscript and functional material object a working playbook is from other compilations of plays' (34). In one of my favourite essays in the collection, Alexandra Johnston embarks on a fascinating piece of literary detective-work into the provenance and nature of the Towneley plays (Huntington Library MS HM 1). Acting on a 'hot tip' from the late Malcolm Parkes (56), Johnston makes a persuasive case that the many quirks and faults of the Towneley manuscript can best be explained 'if the document was compiled for legal purposes', namely, the suppression of Catholic plays in the north (67-8). Matthew Sergi's chapter (71-102) offers a reassessment of the evidence for dating the Chester cycle, combining 'a series of interpretive glosses' on seminal studies by Lawrence Clopper and David Mills that have come to represent two sides of a transatlantic scholarly dispute (72) with fresh analysis of the Antichrist text. Kirsten Inglis and Mary Polito's chapter, 'Noting Baiazet, the Raging Turk' (103-22), makes a convincing argument that the manuscript of Baiazet (Arbury Hall MS A415) is a 'legible and playable, and perhaps publishable' collation of notes produced by 'a team of note-takers' who attended a performance of the play at Oxford in 1619, including John Newdigate, and 'took turns taking notes in a kind of relay' (104). Taking John of Bordeaux as a case study, James Purkis explores 'how performance details may or may not be gleaned from playhouse manuscripts' and whether the play-text 'offers a fascinating and rare link between performance and textual inscription' (124). The 'Production' section closes with William Proctor Williams's chapter, 'James Compton and Cosmo Manuche and Dramatic Manuscripts in the Interregnum' (137-50), which is an effective entrée to whet readers' appetites for hitherto unknown and little-studied Cavalier dramatists.

Although there is no shortage of serious bibliographical and palaeographical analysis, essays in the 'Performance' section shift in focus from the composition of manuscripts to their theatrical use and users. Louise Rayment's careful consideration of the manuscript evidence for adaptation and performance of The Play of Wit and Science neatly bridges the gap between production and performance (153-64). Sarah Carpenter's chapter traces the 'manuscript footprint' of a late-sixteenth Scottish 'disguising' — a mask or mumming — that 'offer[s] little 
purchase for written preservation' (165-6), forcing scholars to rely on 'varied and sometimes oblique manuscript witnesses to reconstruct' both 'the nature' of the events and 'the meanings they seem to have carried for their original spectators' (180). In another of my favourite chapters, Jakub Boguszak explores what one 'can do' with the speeches and silences of actors' parts. After a lively and insightful discussion of examples from Dekker, Jonson, Middleton, Marston, and Shakespeare, Boguszak concludes that this way of approaching familiar texts, 'perhaps better than most other methods of close reading', demonstrates how 'the combination of certainty and ignorance, deliberation and chance' conditioned early modern actors' performances (194). Kara J. Northway's chapter, 'Early Modern Actors' Offstage Textual Rituals' (197-211), argues that the 'early theatre nurtured a distinctive micro-culture of witnessing documents' by tracing 'the collaborative textual activities within and around' Henslowe's Diary: namely, the interactions between borrowers, lenders, and witnesses within the theatre community (198). In 'Comedy, Clowning, the Caroline King's Men' (213-28), Lucy Munro investigates 'what the cast-lists and other aspects of the manuscript texts tell us about individual roles and the requirements that they make on the actors who play them' (215), focusing on comic parts in the Caroline repertory of the King's Men. Daniel Starza Smith and Jana Dambrogio trial a series of prop letters in a production of The Merchant of Venice to ask what letters 'look[ed] like on the early modern stage' and explore 'how might they have signified beyond their written contents' (229). Starza Smith and Dambrogio combine rigorous archival research with a spirit of experimentation, testing letters of different construction and recreating the historical practices of letterlocking to gain fresh insights into these once ubiquitous theatrical manuscripts.

Essays in the 'Reception' section move us outside the playhouse to consider how other agents respond to and engage with dramatic manuscripts, then and now. By close examination of the script-to-print 'remediation' of several manuscript witnesses and fragments of the mid-Tudor Inns of Court play Gismond of Salerne, Tamara Atkin teases out the paradoxical relationship between text and performance: 'it is the process of remediation that makes drama legible, but its legibility always and inevitably effaces the very idea of performance it is designed to articulate' (262). Jean-Christophe Mayer's chapter briefly surveys the manuscript evidence to adduce a variety of early responses to Shakespeare's works (26778). Readers mined Shakespeare for 'reusable extracts' as illustrations of aesthetic beauty and rhetorical prowess (268-9), appreciated the 'quality of the plots of Shakespeare's plays' and his characters (270-2), and attempted, idiosyncratically, to 'classify', 'distinguish', and 'rank' the works, to 'express preference and taste' 
for personal use or the benefit of others with whom they shared their annotations (273-6). Beatrice Montedoro's chapter offers a detailed analysis of a recently rediscovered manuscript in the Bodleian Library (MS Rawlinson D 952). Rather than promoting textual 'continuity and fixity', Montedoro demonstrates that the practice of dramatic extracting also 'encouraged novelty and variation' as compilers selected and adapted the materials to differing - and often non-literary ends (294). This chapter offers an excellent example of the sorts of scholarship now enabled and supported by digital resources, including DEx: A Database of Dramatic Extracts, which Montedoro co-edits with Laura Estill. Antonia Fraser's chapter, 'Seeing is Believing' (297-310), gives an historical account of the notorious eighteenth-century Shakespeare forgeries by William Henry Ireland through the lens of contemporary newspaper coverage and literary reviews, concluding with some tactful remarks about the ongoing media frenzy 'to this day over the re-attribution of Shakespeare's works to other playwrights' (307). In a similar vein, Gail McMurray Gibson charts the Georgian reception of the Macro Plays manuscript (now Folger Shakespeare Library MS V.a.354) — and thus also the genre of English medieval morality play - out of obscurity (311-27). While their scholarly calibre and value are beyond reproach, Fraser's and McMurray Gibson's chapters sit somewhat less comfortably with the rest of the collection because neither engages in analysis of the manuscripts at the heart of their discussion, instead focusing on later paratexts and contexts. In Fraser's case, Edmond Malone's Inquiry may have crushed the Ireland forgery under its 424-page weight, but, as other chapters in the collection have shown, there is always more to be teased out from the manuscript evidence.

The 'Reception' section continues with Matteo Pangallo's chapter, which considers the challenges and opportunities of producing digital editions of early modern manuscript plays, noting how 'the limitation of print can all too easily frustrate users attempting to access evidence of a manuscript play's textual history' (329-30). In 'Mongrel Forms' (345-61), Rebecca Munson's chapter neatly brings the collection back to where it began with questions about the ontological status of dramatic manuscripts. Whereas earlier chapters tackled this question by detailed, meticulous examination of individual manuscripts, Munson adopts a quantitative approach. The result is Common Readers, a database of annotations in early modern printed drama, which — as Munson's chapter demonstrates will allow researchers to identify latent patterns and trends in the data. As with $D E x$ and other digital projects, the work of Common Readers is ongoing, with the promise of further fruits from this labour. 
Finally, a word about the material object itself. Brepols has produced a book of impressive quality, befitting the scholarship it contains. Early British Drama in Manuscript is a weighty volume, literally and intellectually. 
